\title{
RESPONSE OF LAOTIAN MALARIA STRAINS TO CHEMOTHERAPY
}

\author{
ISAO EBISAWA \\ Dept. of Internal Medicine, the Institute of Medical Science, University of Tokyo
}

TATSUKICHI MUTO

Nam Ngum Dam Dispensary

SOHEI KAMEKO

Dispensary of Hazamagumi Construction Co.

GENZO MITSUI

The Japan Association of Tropical Medicine

One hundred and fifteen falciparum and 25 vivax malaria patients who became ill at the Nam Ngum Dam construction site in Laos were treated with 3 treatment schedules. Falciparum malaria patients usually responded excellently to $1500 \mathrm{mg}$ or less of chloroquine base, but R 1 resistance was demonstrated in 4 Japanese and 1 Thai patients. Sulformethoxine-pyrimethamine-quinine (SPQ) and sulformethoxine-pyrimethamine (SP) combination was effective in 18 of 18 and in 25 of 26 patients, respectively. The febrile attack of 25 vivax malaria patients was successfully treated with any of chloroquine, SPQ and SP regimens. Weekly one SP tablet was sufficient to suppress both falciparum and vivax malarias among Japanese workers, 10 percent of which were attacked by falciparum malaria before prophylactic medication was started.

\author{
NATURAL INFECTION WITH THE LARVAE OF \\ DIROFILARIA IMMITIS IN FEMALES OF MOSQUITOES \\ COLLECTED IN DOG-BAITED-TRAPS IN \\ NAGASAKI CITY \\ OSAMU SUENAGA \\ Institute for Tropical Medicine, Nagasaki University \\ TATSUYA ITO \\ Nagasaki City Health Center
}

Mosquito collections by dog-baited-traps, human-baited-traps, and light traps were made in 1968 at three areas, i. e., urban area, suburban area, and agricultural area, in Nagasaki City. Examinations for the relative abundances of mosquitoes in the respective areas were made. By now, the examination was also made for the natural infection of mosquitoes with the larvae of D. immitis col- 